\title{
Alterations in Antioxidant Vitamins in Bronchial Asthma and Its Correlation with Spirometry
}

\author{
Syed Hafeezul Hassan ${ }^{1 *}$, Iftikhar Ahmad ${ }^{1}$, Rubina Ghani ${ }^{2}$, Muhammed Sarwar ${ }^{1}$ \\ ${ }^{1}$ Baqai Medical University, Karachi, Pakistan; ${ }^{2}$ Department of Biochemistry, Baqai Medical University, Karachi, Pakistan. \\ Email: ${ }^{*}$ drhafeez@baqai.edu.pk
}

Received January $20^{\text {th }}, 2013$; revised February $25^{\text {th }}, 2013$; accepted March $27^{\text {th }}, 2013$

Copyright (C) 2013 Syed Hafeezul Hassan et al. This is an open access article distributed under the Creative Commons Attribution License, which permits unrestricted use, distribution, and reproduction in any medium, provided the original work is properly cited.

\begin{abstract}
Bronchial asthma may result in oxidant/antioxidant imbalance. Antioxidant vitamins $\mathrm{E}$ and $\mathrm{C}$ concentrations were estimated in plasma of asthmatics that were also simultaneously subjected to spirometry and matched with healthy controls showing significant changes in both the vitamin concentrations. Vitamin $\mathrm{C}$ showed strong correlation whereas vitamin E was not correlated with spirometry.
\end{abstract}

Keywords: Vitamins E and C; Bronchial Asthma; Spirometry

\section{Introduction}

Anti-oxidants prevent free radical induced tissue damage by preventing the formation of radicals, scavenging them, or by promoting their decomposition. In 2001, Young and Woodside [1] defined an anti-oxidant as "any substance that when present in low concentrations compared to that of an oxidisable substrate significantly delays or inhibits the oxidation of that substrate".

The exogenous chain breaking anti-oxidants include vitamin $\mathrm{E}$ (Vit-E), vitamin A (Vit-A), vitamin C (Vit-C) and a large group of Flavenoids. Vitamins have been defined as organic compounds occurring in natural foods either as such or as "utilizable precursors", which are required in minute amounts for normal growth, maintenance and reproduction i.e. for normal nutrition and health [2].

$\alpha$-tocopherol is the most potent anti-oxidant of the tocopherols and is also the most abundant in humans [3]. The most important lipid phase anti-oxidant is probably Vit-E [4]. Vit-E occurs in nature in eight different forms, which differ greatly in their degree of biological activity. The tocopherols $(\alpha, \beta, \gamma$, and $\delta$ ) have a chromanol ring and aphytyl tail, and differ in the number and position of the methyl groups on the ring. The tocotrienols $(\alpha, \beta, \gamma$, and $\delta$ ) are structurally similar but have unsaturated tails. Both classes of compounds are lipid soluble and have pronounced anti-oxidant properties [5]. They react more

${ }^{*}$ Corresponding author. rapidly than polyunsaturated fatty acids with peroxyl radicals and hence act to break the chain reaction of lipid peroxidation.

The fat soluble Vit-E or tocopherols have been termed as "antisterility vitamin" and "fertility vitamin" due to their role in reproduction [6]. In addition to its anti-oxidant role, Vit-E might also have a structural role in stabilizing membranes [7]. Frank Vit-E deficiency is rare in humans, although it might cause hemolysis and contribute to the peripheral neuropathy. In some newborn infants, red blood cells were subjected to hemolysis by hydrogen peroxide and administration of Vit-E by mouth prevented this hemolysis [8]. In cell membranes and lipoproteins the essential anti-oxidant function of Vit-E is to trap peroxyl radicals and to break the chain reaction of lipid per oxidation. Vit-E will not prevent the initial formation of carbon centered radicals in a lipid rich environment, but does minimize the formation of secondary radicals.

Vit-C (ascorbate) is the most important of the aqueous phase chain breaking anti-oxidants which will directly scavenge radicals present in the aqueous compartment [9]. Ascorbate has been shown to scavenge superoxide, hydrogen peroxide, the hydroxyl radical, hypochlorous acid, aqueous peroxyl radicals, and singlet oxygen [10]. In humans, ascorbate acts as an essential cofactor for several enzymes catalyzing hydroxylation reactions. In most cases, it provide electrons for enzymes that require prosthetic metal ions in a reduced form to achieve full 
enzymatic activity. Vit-C is a free radical scavenger present in the intracellular and extracellular lung fluids and protects against exogenous as well as endogenous oxidants [11]. It is the most abundant antioxidant substance present in the extracellular fluid in the lung which contributes to regeneration of membrane bound oxidized Vit-E to function again [12]. Vit-C is known to have antihistamine effect. It also inhibits the prostaglandin production [13]. In 2005, Boldogh [14] and the other lead authors point out that oxidative insult brought about by pollen exposure can be eliminated if there is sufficient level of anti-oxidants, such as Vit-C with a longer half life. It could be really effective in asthma and allergy treatment and also prevention.

Carotenoids, retinol, and tocopherol are among the most widely studied compounds in various populations, for both serum concentrations and dietary intake [15], because of their inverse relationship with the development of several diseases, e.g., cancer, cardiovascular disease, and cataracts [16].

The imbalance between Reactive Oxygen Species (ROS) and anti-oxidants produce oxidative stress which may be an instrumental for asthma. It can also be implied that asthma like most other chronic illnesses may result into oxidant/anti-oxidant imbalance [17]. Dietary intake, especially of anti-oxidant Vit-E, Vit-A, Vit-C and the carotenoids has been linked with the presence and severity of asthma. The role of nutrition in bronchial asthma is related to anti-oxidant Vit-A, Vit-C and Vit-E. By counteracting oxidants and reducing external attacks (bacteria, virus, toxins, xenobiotics) in the lung, anti-oxidant vitamins modulate the development of asthma and the impairment of pulmonary function [18]. In 2004, Raida et al. [19] showed that serum concentrations of Vit-A and Vit-E were not different between asthmatics and non asthmatics. However, it was shown that low Vit-C and a-carotene intakes are associated with asthma risk in children.

The diagnosis of asthma is usually based on the characteristic symptoms. However, measurements of lung function, particularly the demonstration of reversibility of lung function abnormalities, greatly enhance diagnostic confidence [20]. This is because patients with asthma frequently have poor recognition of their symptoms and poor perception of symptom severity, especially if their asthma is long standing. Concepts of asthma severity and control are important in the evaluation of patients and their response to treatment. The most clinically useful concept of asthma severity is based on the intensity of treatment to achieve good asthma control [21]. Assessment of symptoms such as dyspnoea and wheezing by physicians may also be inaccurate. Measurement of lung function provides an assessment of the severity of air- flow limitation, its reversibility and variability, and provides confirmation of the diagnosis of asthma [22].

Various methods are available to assess airflow limitation, but two methods have gained widespread acceptance. These are measurement of peak expiratory flow rate and spirometry, particularly the measurement of forced expiratory volume in first second $\left(\mathrm{FEV}_{1}\right)$ and forced vital capacity (FVC) and peak expiratory flow (PEF) [20]. Spirometry is the measurement of lung function which provides an assessment of the severity of airflow limitation, its reversibility and variability, and provides confirmation of the diagnosis of asthma [22]. It is essential in monitoring the course of respiratory diseases. The differentiation is made on the basis of reversibility of $\mathrm{FEV}_{1}$ in asthma, whereas COPD shows partial or no reversibility [23]. FVC may be reduced by airflow obstruction as well as by restriction of the airways.

The main objective of this study is to analyze and correlate the exogenous Vit-C and Vit-E with spirometric parameters in asthmatic patients. We measured plasma Vit-C and Vit-E and correlated these with lung function in healthy controls and in patients with asthma. The alteration in vitamins may be targeted as an augmentable treatment and prognostic tool for spirometric parameters.

\section{Materials and Method}

Three hundred and seventy adult patients of both sexes between the ages of $16-70$ years who presented with dyspnoea and history of bronchial asthma or subsequently diagnosed on spirometry were randomly evaluated. The patients were selected from different parts of a thickly populated city of Karachi by organizing various free asthma clinics/medical camps over a period of about one year. Out of which ninety two patients were enrolled in the study who met the inclusion criteria. All other causes of dyspnoea including pneumothorax, pneumonia, pleural effusion, pulmonary fibrosis, anemia, cardiac failure and functional cases of dyspnoea were excluded from the study by carefully evaluating them on clinical grounds including detailed history and clinical examination. Thirty healthy adults of both sexes without any significant past medical/surgical history were subjected to spirometry and their blood samples were drawn for enzymatic, vitamins and trace element analysis.

Portable handheld electronic Spirometer Micromedical plus model 1999 was used. The instrument was calibrated using 3.0 liter calibration syringe by Vitalograph Limited prior to spirometry. Daily calibration was not required with the model used. Spirometry variables were measured for a series of at least 3 acceptable forced expiratory readings [24]. The guidelines by American Thoracic Society (ATS) were followed for obtaining satis- 
factory spirometric values [25]. The best values were selected.

Collection of blood was made under all aseptic measures and 5 milliliters of blood was drawn by venipuncture from a large vein using disposable syringe from Becton and Dickinson (BD). All chemicals were of analytical grade except where stated otherwise. Distilled water, double distilled water and deionized water were used for preparing solutions where required. Disposable plastic made test tubes, containers, pipette tips and centrifuge tubes were preferred. All plastic/glassware was cleaned by soaking in $2 \% \mathrm{HNO}_{3}$ solution and then scouring with bristle brush, followed by extensive tap water rinsing and at least three rinses with distilled water. Glassware was then oven dried at about 80 degree centigrade. Blood sample was then prepared for estimation of vitamins.

The research was conducted after proper approval of the Baqai Medical University Ethical Committee.

\subsection{Determination of Serum Vitamins}

Estimation of serum Tocopherols was done according to the method of Baker and Frank [26]. Ascorbate was estimated according to the method of Harris and Ray [27].

Estimation of serum Tocopherols: (Baker and Frank, 1990).

\section{Principle:}

Serum tocopherols can be measured by their reduction of ferric to ferrous ions which then form a red complex with $\alpha, \alpha$ '-dipyridyl. Tocopherols and carotenes are first extracted into xylene and the absorbance is read at 460 $\mathrm{nm}$ to measure the carotenes. A correction for the carotenes is made after adding ferric chloride and reading at $520 \mathrm{~nm}$.

Estimation of serum Ascorbate: (Harris and Ray, 1990).

\section{Principle:}

The principle is based on the reducing properties of ascorbate or the ketonic properties of dehydroascorbate. Redox titration of ascorbate with 2,6-dichlorophenolindophenol in acidic solution involves reduction of this dye to a colourless leucobase while ascorbate is oxidized to dehydroascorbate.

\subsection{Statistical Data Analysis}

All statistical measurements were performed using statistical software Minitab version 14.

\subsection{Results}

Forty nine females (n-49) and forty three males (n-43) out of ninety two patients (n-92) were between the ages of 16 to 67 years with mean age of $33.98 \pm 11.52$ and $35.91 \pm 12.88$, respectively. Thirty subjects (n-30) were taken as controls out of which nine (9) were females with mean age $31.25 \pm 10.77$ and twenty one (21) subjects were males with mean age $31.05 \pm 12.95$.

\subsection{Spirometry}

The patients were subjected to spirometry and comparison of spirometric values including Forced Expiratory Volume in first second $\left(\mathrm{FEV}_{1}\right)$, Forced Vital Capacity (FVC), Peak Expiratory Flow (PEF) and Percentage Ratio $\left(\mathrm{FEV}_{1} / \mathrm{FVC}\right)$ between patients and controls were applied to all the cases. $\mathrm{FEV}_{\mathrm{I}}$ was $1.91 \pm 0.83$ in patients and $2.93 \pm 0.8$ in controls with highly significant $P$ value $(\mathrm{P}<0.001)$ showing $34.8 \%$ change. $\mathrm{FVC}$ was $2.2 \pm 0.9$ in patients and $3.15 \pm 0.93$ in controls with highly significant $\mathrm{P}$ value $(\mathrm{P}<0.001)$ showing $30.2 \%$ change. $\mathrm{PEF}$ was $247.8 \pm 122.7$ in patients and $428.2 \pm 150.02$ in controls with highly significant $\mathrm{P}$ value $(\mathrm{P}<0.001)$ showing $42.12 \%$ change. However, $\mathrm{FEV}_{1} / \mathrm{FVC}$ was $86.21 \pm 16.6$ in patients and $93.5 \pm 7.15$ in controls, $\mathrm{P}$ value being insignificant $(\mathrm{P}>0.05)$ with only $7.8 \%$ change in patients as expected.

\subsection{Vitamins}

All the subjects were analyzed for Vit-C and Vit-E. The patients (n-92) showed Vit-C and Vit-E value ranging between 5.00 to $13.6(\eta \mathrm{mol} / \mu \mathrm{l})$ with mean value $8.90 \pm$ 1.83 and 36.2 to 44.7 with mean value $40.3 \pm 1.84$, respectively. The controls (n-30) showed Vit-C and Vit-E value ranging between 6.20 to 13.2 with mean value $10.30 \pm 1.92$ and 18.2 to 22.1 with mean value $19.55 \pm$ 0.77 respectively. The $\mathrm{P}$ value was found significant $(\mathrm{P}<$ 0.001 ) showing $13.59 \%$ change and $51.49 \%$ change respectively (Table 1).

Table 1. Comparison of $\mathrm{FEV}_{1}, \mathrm{FVC}, \mathrm{PEF}, \mathrm{FEV}_{1} / \mathrm{FVC}$, Vit-C and Vit-E, between patients and controls.

\begin{tabular}{cccccc}
\hline Variables & Range Patients & $\begin{array}{c}\text { Patients n-92 } \\
\text { Mean } \pm \text { SD }\end{array}$ & Range Control & $\begin{array}{c}\text { Controls n-30 } \\
\text { Mean } \pm \text { SD }\end{array}$ & Significance \\
\hline FEV $_{1}(1)$ & $0.47-3.91$ & $1.91 \pm 0.83$ & $1.6-4.39$ & $2.93 \pm 0.8$ & $<0.001$ \\
FVC $(1)$ & $0.42-5.33$ & $2.2 \pm 0.9$ & $1.63-5.32$ & $3.15 \pm 0.93$ & $<0.001$ \\
FEV $_{1} / \mathrm{FVC}(\%)$ & $44-100$ & $86.21 \pm 16.6$ & $77-100$ & $93.5 \pm 7.15$ & $>0.05$ \\
PEF $(1)$ & $54-595$ & $247.8 \pm 122.7$ & $148-798$ & $428.2 \pm 150.02$ & $<0.001$ \\
Vit-C $(\eta \mathrm{mol} / \mu \mathrm{l})$ & $5-13.6$ & $8.90 \pm 1.83$ & $6.2-13.2$ & $10.30 \pm 1.92$ & $<0.001$ \\
Vit-E $(\eta \mathrm{mol} / \mu \mathrm{l})$ & $36.2-44.7$ & $40.3 \pm 1.84$ & $18.2-22.1$ & $19.55 \pm 0.77$ & $<0.001$ \\
\hline
\end{tabular}




\subsection{Linear Regression}

The correlations were found between spirometric parameters and vitamins. $\mathrm{FEV}_{1}, \mathrm{FVC}, \mathrm{FEV}_{1} / \mathrm{FVC}$ and $\mathrm{PEF}$ were put as independent variable and correlation was found between Vit-C and Vit-E. A significant correlation
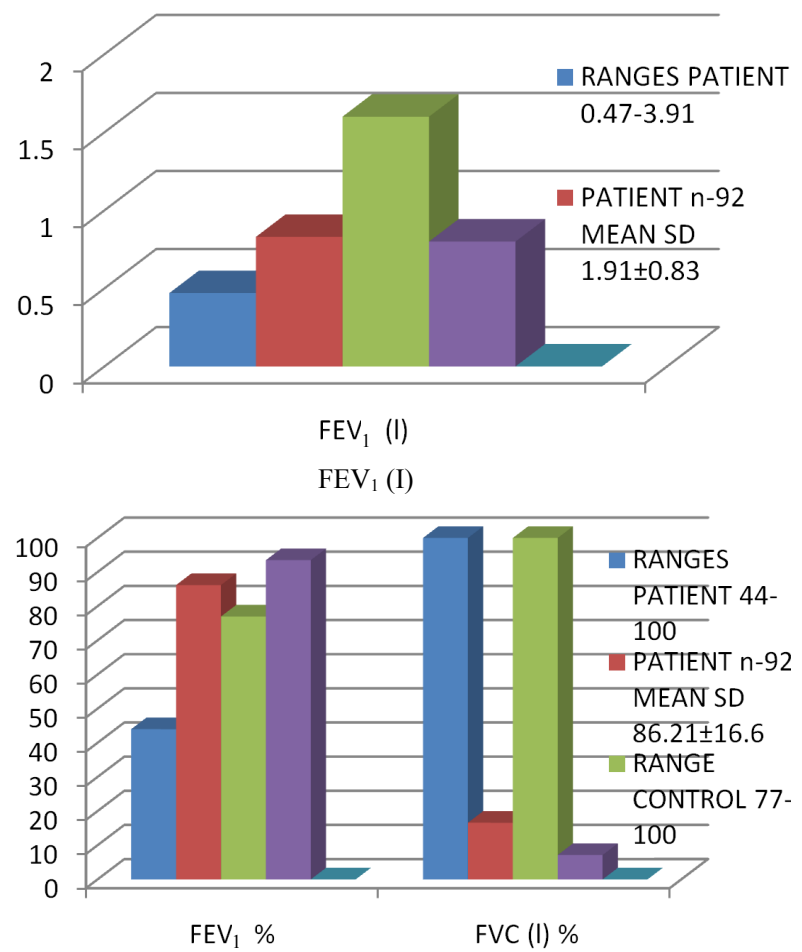

$\mathrm{FEV}_{1} \mathrm{FVC} \%$

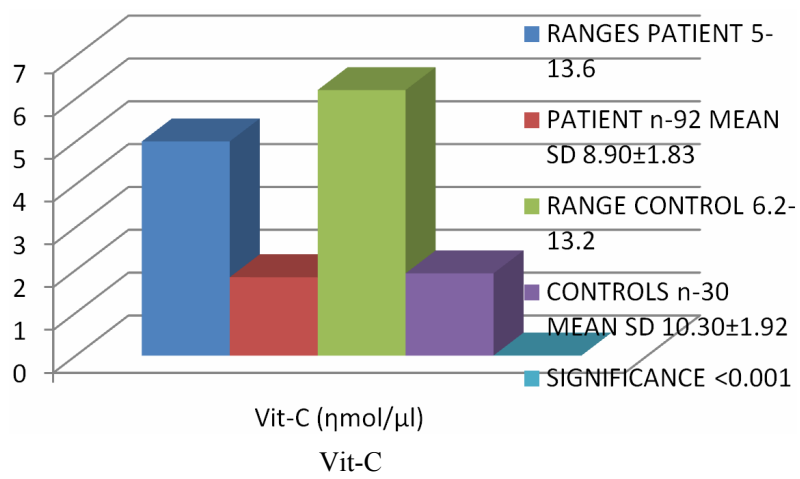

existed between Vit-C and spirometric parameters with $\mathrm{R}^{2}=0.4724, \mathrm{R}^{2}=0.4733, \mathrm{R}^{2}=0.1504$ and $\mathrm{R}^{2}=0.7523$, respectively. Whereas Vit-E and spirometric parameters were insignificant with $\mathrm{R}^{2}=0.0138, \mathrm{R}^{2}=0.0943, \mathrm{R}^{2}=$ 0.2071 and $\mathrm{R}^{2}=0.0628$, respectively.

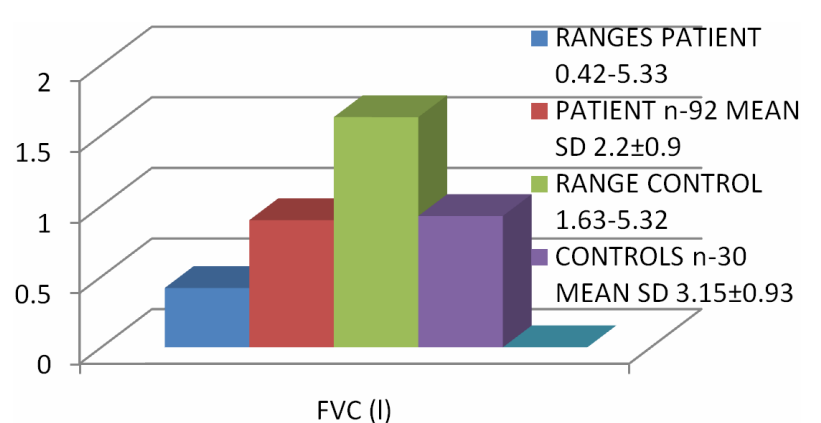

FVC

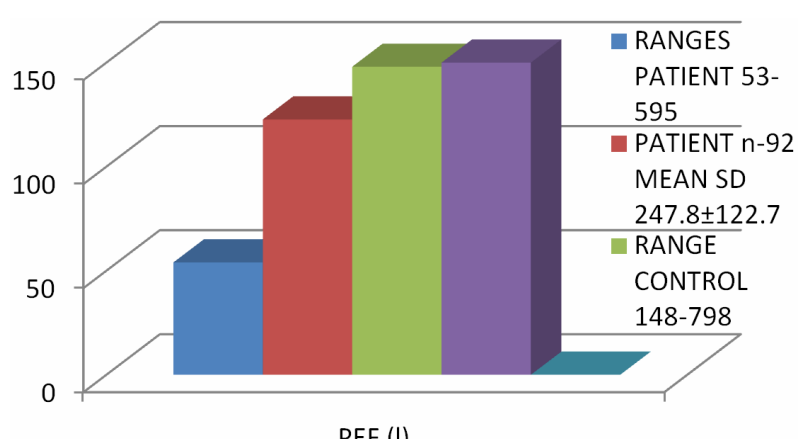

PEF

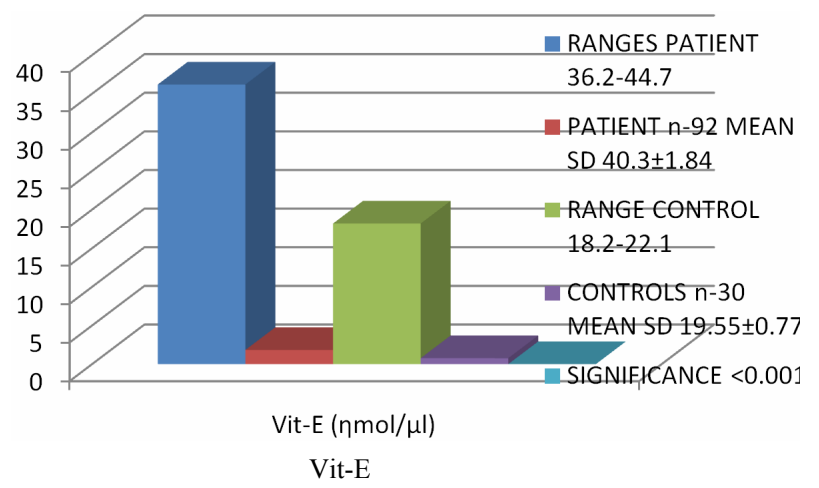

Comparison of $\mathrm{FEV}_{1}$, FVC, PEF, FEV $/$ FVC, Vit-C and Vit-E, between Patients and Controls.

\section{Discussion}

It was hypothesized that alterations in exogenous antioxidant Vit-C and Vit-E occur in asthmatics as part of chronic inflammatory process or due to poor nutrition. The role of nutrition in bronchial asthma is related to anti-oxidant Vit-A, Vit-C, and Vit-E by counteracting oxidants and reducing external attacks for example bacteria, virus, toxins and xenobiotics in the lung, anti-oxidant vitamins modulate the development of asthma and the impairment of pulmonary function [1]. In this study, Vit-E levels were significantly increased in patients when compared to controls although they remained within the normal range as suggested by Raida [28]. This may indicate impairment in utilization of the vitamins. Similar to our results for asthmatics, Caye-Vaugien [29] showed Vit-E levels in diabetic patients as higher or similar in comparison with controls, possibly because of inclusion of hyperlipemic or inhomogeneity of the sample or both. However, decrease in vitamins was seen in asthmatics 
who were taking bronchodilators, the first line asthma treatment [30]. There is evidence of an inverse association between Vit-E intake and both allergen skin sensitization and total serum IgE levels in adults. High Vit-E intake is associated with reduced asthma incidence [31].

Anti-oxidants are important in restoring the disturbed oxidant/anti-oxidant equilibrium in patients with asthma. Anti-oxidants selenium, magnesium, Vit-A and Vit-C as well as glutathione are lower in asthmatics than in people without asthma [32]. In our findings, Vit-C levels were significantly decreased in patients when compared to controls. It indicates that ascorbate plays important role in progression of asthma. It has been reported that the administration of Vit-C can sometimes lead to an increase in oxidative damage, particularly if iron is also administered [33]. This might be crucial in ensuring that tocopherol concentrations are maintained in lipoproteins and membranes [34]. Therefore, increased serum concentration of Vit-E and simultaneous decrease in concentration of Vit-C may be pertinent in this study on asthmatics. It is suggested that various anti-oxidant vitamins may be used in the treatment of asthma which have been successfully used therapeutically in other chronic inflammatory disorders.

A significant correlation existed between Vit-C and $\mathrm{FEV}_{1}, \mathrm{FVC}, \mathrm{FEV}_{1} / \mathrm{FVC}$ and PEF with $\mathrm{R}^{2}=0.4724, \mathrm{R}^{2}=$ $0.4733, \mathrm{R}^{2}=0.1504$ and $\mathrm{R}^{2}=0.7523$ whereas Vit-E and $\mathrm{FEV}_{1}, \mathrm{FVC}, \mathrm{FEV}_{1} / \mathrm{FVC}$ and PEF were not correlated with $\mathrm{R}^{2}=0.0138, \mathrm{R}^{2}=0.0943, \mathrm{R}^{2}=0.2071$ and $\mathrm{R}^{2}=$ 0.0628 , respectively.

\section{Conclusion}

The effects of asthma on anti-oxidant Vit-E and Vit-C status showed significant change. Vit-C showed strong correlation with spirometry whereas Vit-E was not correlated.

\section{REFERENCES}

[1] I. S. Young and J. V. Woodside, "Antioxidants in Health and Disease," Journal of Clinical Pathology, Vol. 54, No. 3, 2001, pp. 176-186. doi:10.1136/jcp.54.3.176

[2] M. N. Chatterjea and R. Shinde, "Vitamins, Text Book of Biochemistry," Jaypee Brothers Medical Publishers, New Dehli, 2005, p. 144.

[3] G. W. Burton and K. U. Ingold, "Vitamin E: Applications of the Principles of Physical Organic Chemistry to the Exploration of Its Structure and Function," Accounts of Chemical Research, Vol. 19, 1986, pp. 194-201.

[4] H. Esterbauer, R. J. Schaur and H. Zollner, "Chemistry and Biochemistry of 4-Droxnonenal, Malonaldehyde and Related Aldehydes," Free Radical Biology and Medicine, Vol. 11, No. 1, 1991, pp. 81-128. doi:10.1016/0891-5849(91)90192-6

[5] M. H. Horwitt, "Data Supporting Supplementation of
Humans with Vitamin E," The Journal of Nutrition, Vol. 121, No. 3, 1991, pp. 424-429.

[6] E. S. West, W. R. Todd, H. S. Mason and J. T. Van Bruggen, "The Vitamins. Text Book of Biochemistry," The Macmillan Company, London, 1984, p. 764.

[7] S. Urano, Y. Inomori and T. Sugawara, et al., "Vitamin-E-Inhibition of Retinol-Induced Hemolysis and Membrane Stabilizing Behavior," Journal of Biological, Vol. 267, 1992, pp. 18365-18370.

[8] P. Gyorgy, C. Cogan and C. S. Rose, "Vitamin E and Prevention of Hemolysis," Proceedings of the Society for Experimental Biology and Medicine, Vol. 81, 1952, p. 536.

[9] M. Levine, S. C. Rumsey and R. Daruwala, "Criteria and Recommendations for Vitamin C Intake," Journal of the American Medical Association, Vol. 281, No. 15, 1999, pp. 1415-1423. doi:10.1001/jama.281.15.1415

[10] P S. ietri, J. R. Seguin and P. Darbigny, "Ascorbyl Freeradical, a Noninvasive Marker of Oxidative Stress in Human Open Heart Surgery," Free Radical Biology and Medicine, Vol. 16, No. 4, 1994, pp. 523-528. doi:10.1016/0891-5849(94)90131-7

[11] R. J. Troisi, W. C. Willett, S. T. Weiss, D. Trichopoulos, B. Rosner and F. E. Speizer, "A Prospective Study of Diet and Adult Onset Asthma," American Journal of Respiratory Cell and Molecular Biology, Vol. 151, 1995, pp. 1401-1408.

[12] W. I. Aderele, S. I. Etle and O. Oduwole, "Plasma Vitamin C (Ascorbic Acid) Levels in Asthmatic Child," African Journal of Medicine \& Medical Sciences, Vol. 14, No. 3-4, 1985, pp. 115-120.

[13] F. Chtil, "The Lungs and Vitamin A," American Journal of Physiology, Vol. 262, No. 5, 1992, pp. 262-265.

[14] I. Boldogh, A. Bacsi, N. Dharajiva, B. Choudhury, T. Hazra, S. Mitra, R. Goldblum, S. Sur and Alam, "Discovery that Oxidative Stress from Pollen Is as Important as Antigen Exposure Could Lead to New Therapies," American Journal of Epidemiology, Vol. 162, 2005, pp. 1137-1145.

[15] A. Sommer, "Vitamin A Deficiency and Clinical Disease: An Historical Overview," The Journal of Nutrition, Vol. 138, No. 10, 2008, pp. 1835-1839.

[16] J. Thompson and M. Manore, "Nutrients Involved in Antioxidant Function, Nutrition, an Applied Approach," Pearson Education Inc. Publishers, Upper Saddle River, 2005, pp. 276-283.

[17] I. Hanta, S. Kuleci, N. Canacankatan and A. Kocabas, "The Oxidant-Antioxidant Balance in Mild Asthmatic Patients," Lung, Vol. 181, No. 6, 2003, pp. 347-352. doi:10.1007/s00408-003-1037-7

[18] G. Riccioni, M. Barbara, T. Bucciarelli, C. Di Ilio and N. D'Orazio, "Antioxidant Vitamin Supplementation in Asthma," Annals of Clinical \& Laboratory Science, Vol. 37, No. 1, 2007, pp. 96-101.

[19] R. I. Harik-Khan, D. C. Muller and R. A Wise, "Serum Vitamin Levels and the Risk of Asthma in Children," American Journal of Epidemiology, Vol. 159, No. 4, 2004, pp. 351-357. doi:10.1093/aje/kwh053 
[20] Eric and Coworkers, "Global Initiative for Asthma Gina Executive Committee, Global Strategy for Asthma Management and Prevention," 2009. www.ginasthma.org

[21] D. R. Taylor, L. P. Bateman, H. Boulet, et al., "A New Perspective on Asthma Severity and Control," European Respiratory Journal, Vol. 32, No. 3, 2008, pp. 545-554. doi:10.1183/09031936.00155307

[22] K. J. Killan, R. Waston, J. Otis, T. A. St Amand, P. M. O’Byrne, "Symptom Perception during Acute Bronchoconstriction," American Journal of Respiratory and Critical Care Medicine, Vol. 162, 2000, pp. 4902-4906.

[23] P. J. Barnes and S. Godfrey, “Asthma," Martin Dunitz Ltd., London, 1995, pp. 14-22.

[24] J. E. Cotes, "Lung Function-Assessment and Application in Medicine," 5th Edition, Oxford Blackwell Scientific Publication, London, Edinburgh, Paris, Berlin, Melbourne, Boston, Vienna, 1994, pp. 134-150.

[25] American Thoracic Society, "Standardization of Spirometry: 1994 Update," American Journal of Respiratory and Disease, Vol. 152, 1995, pp. 1107-1136.

[26] Baker and Frank, "Varley Harold Practical Clinical Biochemistry," Heinemann Medical Books, 6th Edition, London, 1990.

[27] Harris and Ray, "Varley Harold Practical Clinical Biochemistry," Heinemann Medical Books, 6th edition, London, 1990.

[28] R. I. Harik-Khan, D. C. Muller and R. A. Wise, "Serum
Vitamin Levels and the Risk of Asthma in Children," American Journal of Epidemiology, Vol. 159, No. 4, 2004, pp. 351-357. doi:10.1093/aje/kwh053

[29] C. Caye-Vaugien, M. Krempf, P. Lamarche, B. Charbonnel and J. Pieri, "Determination of Alpha-Tocopherol in Plasma, Platelets and Erythrocytes of Type I and Type II Patients by HPLC," International Journal for Vitamin and Nutrition Research, Vol. 60, 1990, pp. 324-330.

[30] M. R. Weir, "Depression of Vitamin B6 Levels Due to Theophylline," Annals of Allergy, Vol. 65, No. 1, 1990, pp. 59-62.

[31] P. I. Collipp, "Tryptophane Metabolism in Bronchial Asthma," Annals of Allergy, Vol. 35, No. 3, 1975, pp. 153-158.

[32] H. M. Oberholzer and E. Pretorius, "The Role of Vitamins and Minerals in the Alleviation of Asthma Symptoms," Early Child Development and Care, Vol. 180, No. 7, 2010, pp. 913-920. doi:10.1080/03004430802525047

[33] J. Suh, B. Z. Zhu and B. Frei, "Anti- and Pro-Oxidant Effects of Ascorbate on Iron-Mediated Oxidative Damage to Bovine Serum Albumin," Free Radical Biology \& Medicine, Vol. 27, 1999, p. 305s.

[34] J. M. May, Z. C. Qu and S. Mendiratta, "Protection and Recycling of Alpha-Tocopherol in Human Erythrocytes by Intracellular Ascorbic Acid," Archives of Biochemistry and Biophysics, Vol. 349, No. 2, 1998, pp. 281-289. doi:10.1006/abbi.1997.0473 